\title{
La formación inicial y la cultura profesional de los policías
}

Este documento presenta una investigación longitudinal realizada con 1167 reclutas de la $121^{a}$ promoción de alumnos guardianes de la paz de la Policía Nacional (Francia), que ingresó en enero de 1992 y egresó en diciembre del mismo año. El estudio estuvo a cargo del Institut des Hautes Etudes de la Sécurité Intérieure (IHESI). Su objetivo fue comprender las modalidades y los contenidos de la socialización profesional, los procesos en virtud de los cuales los jóvenes que han ingresado a la Policía son transformados por el contacto con sus colegas, y la experiencia profesional acumulada de cara a la cultura profesional propia. Los recursos utilizados en el estudio incluyen cuestionarios periódicamente administrados y fotografías que posibilitan advertir los cambios externos en la población, a medida que van integrándose en el universo profesional policial.

La población objeto de estudio mostró 3 puntos en común, a saber:

1. Más de 4 quintas partes de los reclutas conocen personalmente a policías o gendarmes, y más de la tercera parte mantiene lazos familiares con policías. A juicio de los autores, este vínculo pesa más que la publicidad, para decantarse por esta opción profesional.

2. Demuestran esperanzas y confianza en la institución, ya que manifiestan unanimidad en cuanto a las posibilidades de hacer carrera y de promocionarse en ella.

3. Conciben su profesión como generalista y polivalente, apoyados por un saber empírico y una verdadera cualificación. No es significativa la concepción de una Policía centrada en el combate a la delincuencia y distante del público.

Se advierten además 4 factores de diferenciación entre la población objeto de estudio: 


\section{WEB}

1. En relación a las motivaciones de la elección profesional, se advierten 2 polos: Los que han decidido ser policías y afirman que en un contexto diferente optarían siempre por ello; y los que han optado por un empleo en la función pública y que habrían preferido eventualmente otro. Los primeros son más numerosos que los segundos y, en todo caso, la vocación es un factor importante de reclutamiento.

2. Una quinta parte son del sexo femenino. Son más jóvenes y muestran con frecuencia una motivación más fuerte; presentan mayor optimismo frente al trabajo, respeto por las reglas y menor inclinación al uso de la fuerza. Llama la tención que en lo referente al uso de las armas, muestran igual o mayor propensión que los reclutas.

3. La experiencia policial se ha dado por 2 vías: La afiliación y el servicio militar obligatorio que se puede prestar como policía auxiliar o como gendarme auxiliar. Los que se vinculan afiliándose con la Policía, se muestran más motivados y optimistas; en tanto los que han tenido experiencia previa, se muestran menos motivados y escépticos.

4. En relación con la ley, se advierten 3 representaciones de la norma: Para unos es un obstáculo para la eficacia policial, para otros un marco necesario para la vida en sociedad y, para los otros, es simplemente la transcripción o codificación de un conjunto de valores. Esto señala un punto central para la enseñanza en términos del aprendizaje de la deontología.

Al cabo de un año, se observó en la población una reubicación de las expectativas y de los proyectos iniciales marcada por un mayor realismo. Hay un desencanto relativo más a la institución policial que a la profesión y un desencanto relativo a las relaciones de la profesión, así como a la relación Policía-público. Es posible advertir 5 ámbitos principales en relación a sus opiniones y actitudes:

1. Manifiestan críticas a la formación por contenidos que no han respondido a sus expectativas, así como por los métodos empleados; en tanto que los formadores han sido valorados en manera desigual. En este punto la crítica de fondo es que la función policial solo puede ser aprendida en la práctica y a través del ejemplo de los policías veteranos. Se reproduce la disyuntiva sobre 2 modelos de aprendizaje de la función policial, a saber, la escuela y la calle. 
2. La concepción inicial sobre la profesión tiene un cambio significativo. Se potencia la idea del guardián de la paz polivalente. La honestidad aparece como la virtud cardinal. La concepción sobre la vocación marca diferencias. Para unos, la profesión se define sustancialmente por tareas y responsabilidades; otros entienden la profesión en términos de empleo y condiciones de trabajo. Es importante ver que mientras un grupo ha aceptado la formación, otros la han rechazado al endurecer sus posturas contra la norma en el ejercicio de la función policial.

3. Las ideas sobre las concepciones de la función policial, tareas y medios; se van aproximando a la visión de la Policía centrada en las tareas represivas, especialmente en el control de la delincuencia. Las mujeres doblan a los hombres en su inclinación por un modelo de Policía de servicio público de proximidad, generalista, con misiones extensas. Por unanimidad, la población encuestada señala que la Policía cuenta con medios insuficientes para el desarrollo de su labor; pero un tercio se divide en 2 visiones: Para unos, los policías están bien formados, motivados y la organización de los servicios es eficaz; para otros, los policías están mal formados, carecen de motivación y la organización debe ser revisada.

4. Se advierte una erosión de las expectativas relacionales, dado que la percepción sobre policías municipales y la seguridad privada ha sufrido un serio deterioro. Por el lado de la relación con la sociedad, aparece una pluralidad de concepciones, destacando la de quienes afirman que los policías están en una torre de marfil, y la de quienes afirman que son portadores de un modelo de servicio público que no se absorbe en una administración centralizada, atemperada por la preocupación de proteger la imagen de la Policía y el grupo.

5. Se advierte un posicionamiento diferencial de los reclutas en su relación con la ley, advirtiendo que las concepciones originalmente observadas en enero, no han cambiado en lo sustancial a diciembre, manteniendo las actitudes que registraron al inicio del estudio. Es posible afirmar en este caso que la escuela no inculca una doctrina que sea a la vez clara y fuerte. Si la escuela enseña reglas, prescripciones y normas, no es evidente que enseñe eficazmente la razón en el doble sentido de fundamento (el Estado de derecho) y de comprensión de las mismas (civismo).

El estudio concluye que la socialización impartida por la escuela, es apenas un esbozo que se complementa y confirma mediante el contacto con los colegas y el público en el terreno. Los rasgos esenciales de este proceso son: 


\section{WEB}

La adopción masiva de una serie de estereotipos definidos por la cultura profesional policial, siendo el núcleo duro de tales estereotipos, la actitud ante los medios de comunicación. Es importante señalar que, aun cuando la honestidad aparece como la cualidad elemental y primaria requerida por la profesión, la tensión entre efectividad policial y el cumplimiento de la norma tiende a aparecer para la mayoría de los reclutas.

Los ejes sobre los que se posicionan los reclutas son: La relación con el público y la relación con la ley. De su postura en estos campos se derivan sus posiciones en otros ámbitos de la actividad profesional, así como la forma e intensidad de su identificación con la profesión policial.

A la luz de los hallazgos, la enseñanza de la escuela no destila una ortodoxia obligada. Sin embargo, cabe reflexionar sobre el deseable equilibrio entre el respetable y necesario pluralismo de las opiniones y la adhesión a un núcleo de principios de cara a lo que significa la fuerza pública y los medios para el logro de sus fines.

\section{Relevancia del estudio}

La naturaleza del estudio, sustancialmente longitudinal, es de gran valor metodológico para evaluar el impacto de la formación policial, dado que permite valorar paulatinamente las modificaciones observadas en las percepciones y en el estilo de vida de los policías en formación.

Es significativo apreciar que el estudio revela, tal como ocurre actualmente en El Salvador, la afiliación como un factor significativo para la incorporación a la profesión de policía, siendo este hecho más importante que la publicidad. Igual relevancia reviste el hecho de identificar un número significativo de personas que buscan la profesión policial como un medio para ganarse la vida, y la valoración en torno al hecho que ello no niega la vocación como algunos lo han pretendido señalar en el caso salvadoreño.

De la misma suerte, es importante advertir que hay elementos propios de la cultura policial que están presentes en diversas latitudes, tales como las concepciones en torno a las normas y la efectividad policial, la relación con los medios de comunicación, la relación con otros actores de seguridad privados, y la relación con la comunidad misma.

El estudio ahora comentado, confirma retos en torno a la formación policial de cara a su efectividad más allá del deber ser, respondiendo a las inquietudes presentes en todos los cuerpos policiales que argumentan que las instituciones de formación se alejan de la realidad policial; pero 
reafirman lo que desde siempre se ha dicho en los centros de formación: Que la preparación del personal policial no concluye con el egreso del centro de formación, sino más bien, se consolida y potencia con la articulación entre la formación y el desarrollo de la profesión que se realiza en el ejercicio de la función policial, como síntesis entre los marcos normativos (legales, deontológicos y procedimentales) con las exigencias de un entorno social concreto.

Otro reto presentado por el estudio, es el de lograr una efectiva formación en el ámbito deontológico. El evidenciar que luego de un año de formación las actitudes sobre la norma jurídica no se modifican, y que por el contrario han ido endureciéndose, aunado al rechazo a los medios de comunicación y al deterioro de las expectativas relacionales; indica que la universalización de la concepción verdaderamente democrática de la función policial es aún tarea pendiente en el mundo. La sola percepción de la ley como un freno a la función policial, debe ser tema de preocupación para cualquier ciudadano. Si la función pública ha de concebirse como un servicio del Estado a la ciudadanía, tal servicio no puede estar restringido al desarrollo adecuado de una determinada técnica de intervención; lejos de ello, exige que todo procedimiento sea valorado y aplicado a la luz de una concepción verdaderamente comunitaria de la labor policial.

Otro hallazgo que llama a reflexión, es la necesaria participación de la mujer en la Policía. Si esta ha de ser representativa de la sociedad a que sirve, es menester que refleje la conformación de la sociedad en su conjunto. Queda como tarea a estudios nacionales verificar si las cualidades exhibidas por las reclutas participantes del estudio realizado son replicadas por las mujeres en El Salvador, lo cual sería una razón de más peso para potenciar la progresiva y significativa participación de la mujer en la institución policial.

Otro reto evidenciado para las instituciones de formación policial, es la real valoración del currículo oculto, dado que el estudio indica que la percepción de la labor policial, más allá de la represión del delito, va cediendo paso a las concepciones que ponen énfasis a la función represiva de la Policía. Algo no está funcionando bien en los procesos formativos si tal es el caso.

Sinopsis elaborada por José Antonio Guzmán Cardona

Director de Investigaciones

Instituto Especializado de Nivel Superior Academia Nacional de Seguridad Pública (IES-ANSP) 